\title{
Ubiquitous Flipped Classroom Instructional Model with Learning Process of Scientific to Enhance Problem-Solving skills for Higher Education (UFC-PS Model)
}

\author{
Ekkharin Srilaphat ${ }^{1} \&$ Thada Jantakoon ${ }^{2,3}$ \\ ${ }^{1}$ Department of Computer Science, Faculty of Science and Technology, Rajabhat Maha Sarakham University, \\ Mahasarakham, Thailand \\ ${ }^{2}$ Faculty of Science and Technology, Rajabhat Maha Sarakham University, Mahasarakham, Thailand \\ ${ }^{3}$ Department of Educational Technology and Computer Education, Faculty of Education, Rajabhat Maha \\ Sarakham University, Mahasarakham, Thailand \\ Correspondence: Thada Jantakoon, Faculty of Science and Technology, Rajabhat Maha Sarakham University, \\ Mahasarakham, Thailand. Tel: 66-961-694-277. E-mail: thada.phd@gmail.com
}

Received: November 25, 2018

doi:10.5539/hes.v9n1p76
Accepted: December 14, 2018 Online Published: December 26, 2018

URL: https://doi.org/10.5539/hes.v9n1p76

\begin{abstract}
This research aimed at proposing an ubiquitous flipped classroom instructional model with learning process of scientific to enhance problem-solving skills for higher education (UFC-PS model). The UFC-PS model was developed based on the review of the literature, the expert's interview and evaluated by five experts. The research results were found that the UFC-PS model consists of three components were (1) Ubiquitous Learning Environment, (2) Ubiquitous Scaffolding, and (3) flipped classroom through scientific inquiry. The experts also evaluated which step of the UFC-PS model was most suitable for the development of the respective aspects of problem-solving skills.
\end{abstract}

Keywords: ubiquitous, flipped classroom, learning process of scientific, problem solving, UFC-PS model

\section{Introduction}

Ubiquitous Learning (u-Learning) refers to a learning model in which the learners can learn anywhere anytime with the aid of mobile computer technology and wireless communication; and thereby, the said learning must emphasize a context-awareness of the learners. The term "u-learning" stands for ubiquitous learning. The word 'ubiquitous' means everywhere. The integration of that with the word 'learning' emphasizes a learning model that allows learners to gain knowledge anywhere anytime by using portable computer technology and wireless communication as tools. The learning recognizes learner's context. The so-called ubiquitous learning environment (ULE) is a setting that contributes to pervasive study. Learning can happen anywhere anytime with a portable computer mediating an access to knowledge sources (Premsmith et al., 2017).

Problem-based Learning (PBL) is based on the theories of constructivism, where the students' generate new knowledge from the problems of the real world (Chatwattana \& Nilsook, 2017), and is considered a learning context to help the students to increase problem-solving skills. According to the National ICT Policy Framework 2011-2020, education in Thailand is projected to step into "Smart Learning", which continually supports the development and application of ICT learning media for educational personnel. This will lead to a lifelong learning society.

In a flipped classroom environment, students can access to learning contents related to new topics they will learn through such materials as lecture videos out-of-class mobile learning where they have face-to-face in-class interactive learning (Jantakoon \& Piriyasurawong, 2018) and is considered ubiquitious. Later, students work on assimilating the new material they learned through such methods as project work activities in the classroom, cooperative learning, and group discussions and through videos.

The important characteristic of the UFC-PS model is focusing on active learner of active learning in small group classes and comes from knowledge searching for using for solving problems that have been assigned. The process of learning will run systemically step by step, acquiring up-to-date knowledge and it can be applied for 
the student in the real life which is effective for teaching and also it is unlimited to disseminate the knowledge into others sciences. UFC-PS model usage is a strategy that encourages students to develop problem-solving skills and the student is able to apply knowledge to solve problems effectively. Therefore, it is very necessary to develop problem-solving skills for making the learning skills to students.

\section{Literature Review}

\subsection{Ubiquitous Learning Environment}

The definitions and descriptions of ubiquitous learning and ubiquitous learning environments (ULE) have varied and have diversified with multiple spectacles such as augmented and mobile learning (McCall et al. 2011; Cheng \& Tsai, 2013). Distinguishing the differences between ubiquitous and mobile learning environments has been seen as challenging because of unsubstantiated terminology (Yahya et al., 2010). In general, m-learning can be defined as any form of learning mediating through a portable device (Alexander, 2004). In educational use, portable devices offer mobility and ubiquitous access providing situated learning opportunities and change the way to study and learn. M-learning enables social connectivity and interactivity between devices, individuals, networks, and other technologies (Melhuish \& Falloon, 2010). The first m-learning environments were published in 2000 (Quinn, 2000), followed by descriptions of ULEs (Ogata \& Yano, 2004). This study focuses on ULEs, which have not been widely studied in the higher education context. The differences between u- and m-learning environments are context-aware and personalized learning activities with the use of functional objects, mobile devices, and sensing technologies wireless networks. Thus, the ULE is generally seen as a broader entity than the use of portable devices in learning.

ULE integrates authentic functional objects, omnipresent digital resources, learning space, mobile devices, sensing technologies and wireless networks with the functional characters. It enables studying and learning on demand, based on students' personal needs and own activity. ULEs are flexible, context-aware, interactive and personalized (Marinagi et al., 2013; Martin \& Ertzberger, 2013), learning resources provided in relevant time and location (Yahya et al., 2010). Context-aware actions have been found as relevant as well as the use of sensing technologies. Interactivity and collaboration have been reported as supportive of learning (Hwang et al., 2011; White \& Turner 2011). Personalized support and instructions have been seen as relevant (Huang et al., 2012), and immediate feedback has promoted the effectiveness of learning performance (Tsai et al., 2015).

\subsection{Flipped Classroom}

A flipped classroom approach consists of two distinct parts: direct on-line instruction at the students' own time and pace, and interactive group learning activities in scheduled classes (Comber \& Brady-Van den Bos, 2018). Course content can be presented in the form of readings, graphical, videos presentations or quizzes (Hanson, 2016). These online 'lectures' are followed up with lecturer run workshops within which students engage with the recently delivered course materials, thus putting theory into practice. Such sessions typically include elements of collaborative, interactive and applicative engagement in problem solving (Bishop \& Verleger, 2013; Lavelle et al., 2013).

Students in the 21 st Century require a wide range of 'soft' skills and knowledge occurring in authentic learning situations and include greater communication, collaboration, problem-solving and critical thinking (Snape, 2017). The utilization of the flipped classroom approach has increased in response to this change in learning practices of students who also increasingly tend to access information via ICT (Hanson, 2016). Blair et al., (2016) and Serdyukov (2015) suggest recent ICT advances have assisted the facilitation of the shift in tertiary teaching from the traditional teacher-centered approach to a learner-centered approach.

Conversely, the flipped classroom approach holds a number of challenges and disadvantages. Mason, Shuman, and Cook (2013) identified three major difficulties with the flipped classroom approach 1) time computation, 2) student discomfort with taking responsibility for their own learning, 3) discrepancies in the literature about the flipped approach in some courses. Johnson and Renner (2012) suggest a strong work ethic is needed for success in the flipped classroom environment both from the teachers' and students' points-of-view. Furthermore, not all students will be inclined to view the materials prior to their workshop classes. In addition, the development of the materials is labor intensive (Lavelle et al., 2013) for lecturers and video materials may not very easily be corrected or modified. Mason et al. (2013) state their biggest concern is flipped classroom pedagogy. The approach assumes that students have online access; this can prove difficult for students in rural areas and the assumption that students have the pre-requisite skills and web-based technology necessary for successful implementation. This could result in students becoming disengaged and leave their courses. Many university campus classrooms have been designed for a traditional lecture approach to teaching. This setting makes mobility and collaborative work desirable in the flipped approach, a challenge (Carpenter et al., 2015). Therefore, 
before undertaking a significant shift to a broad-ranging flipped approach it is critical for universities to explore the feasibility of this approach.

\subsection{Information Problem Solving}

In educational settings, teachers often use information problems, where significant information to solve the problem is insufficient, as an educational approach. The student is required to gather the missing information from external sources and coordinate the findings to construct a solution. Simple information problems, such as looking up the average monthly temperature in a country, pose little challenge for students. Complicated information problems, such as writing an essay on the effects of global warming on biodiversity, are a far more difficult challenge because students will need to find process and evaluate sources of information that can vary greatly in terms of their trustworthiness, bias, reliability, or can comprise contradictory information. Teachers often expect that having students search for information will automatically lead to their learning (Kirschner, Sweller, \& Clark, 2006). Nevertheless, correctly and efficiently solving an information problem is a complex higher-order cognitive competence requiring a broad range of different cognitive skills that these students might not possess. The range of skills has been summarized as a 5 step model in which students iterate between the stages 1) define the problem, 2) search information, 3) select information, 4) process information and 5) present information', each step consisting of several constituent skills (Brand-Gruwel, Wopereis, \& Walraven, 2009) (refer to Figure 1).

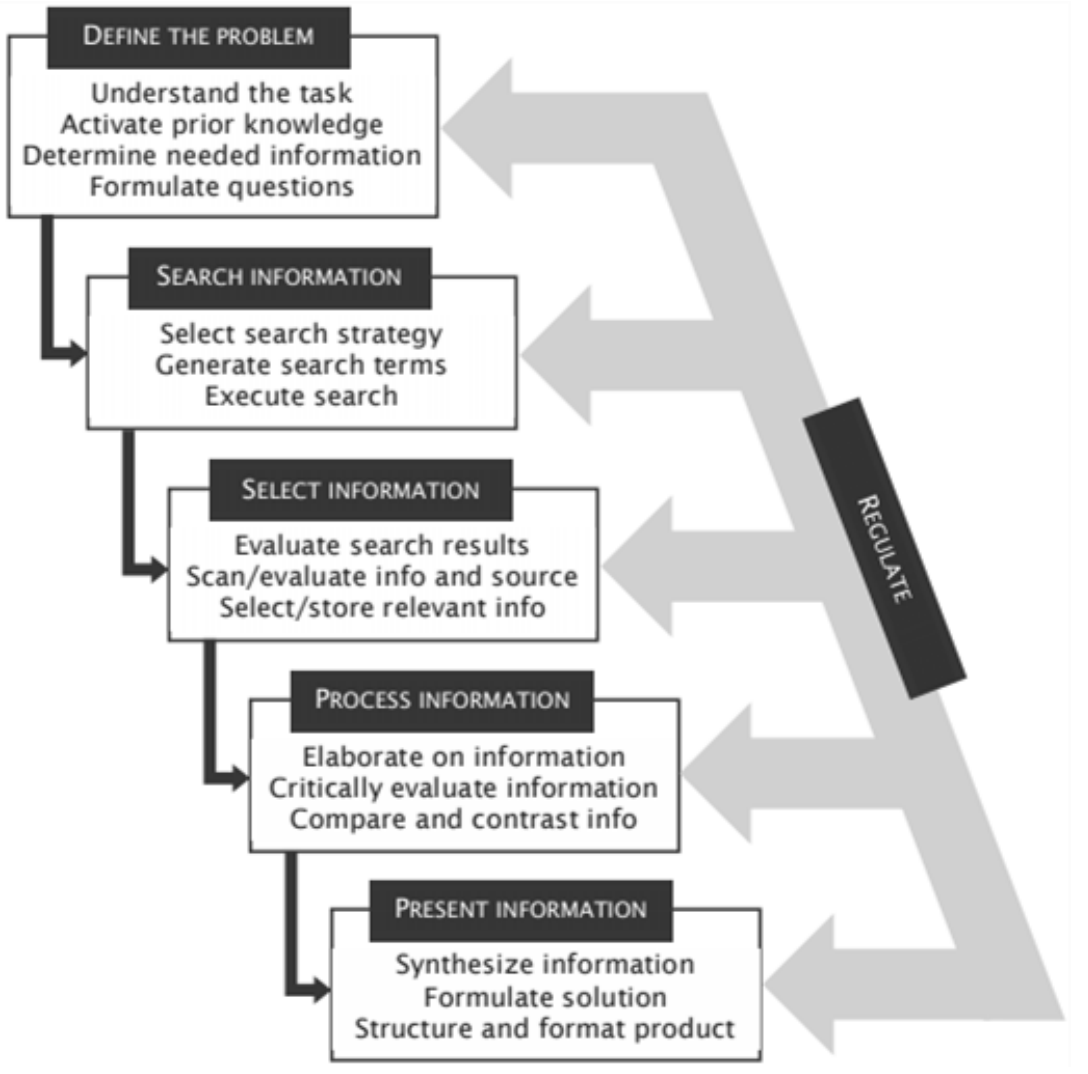

Figure 1. Overview of the skill 'information problem solving' (Brand-Gruwel et al., 2005)

\subsection{Science Process}

Science process skills are known as procedural skills, investigating and experimental science habits of mind or scientific inquiry abilities (Harlen, 1999). Appropriate selections of science process skills can be taught and studied the basic skills considered as a prerequisite to learning the integrated skills. The students can be given the opportunity to observe, handle things and explore the environment (Ango, 2002). Chiappetta and Koballa, (2002) categorized basic and integrated scientific skills as follows:

\subsubsection{Basic Science Process Skills}

- Observing: Noting the properties of objects and situations using the five senses. It is description of what was actually perceived. 
- Measuring: Expressing the amount of an object or substance in quantitative terms.

- Inferring: Giving an explanation for a particular object or substance in quantitative terms.

- Classifying: Relating objects and events according to their properties or attributes.

- Predicting: Forecasting a future occurrence based on past observation or the extension of data.

- Communicating: Using words, symbols, or graphics to describe an object, action or event.

2.4.2 Integrated Science Process Skills

- Controlling variables: Manipulating and controlling properties that relate to situations events for the purpose of determining causation.

- Hypothesizing: Stating tentative generalization of observations or inferences that may be used to explain a relatively larger number of events but that is subject to immediate or eventual testing by one or more experiments.

- Experimentation: Testing a hypothesis through the manipulation and control of independent variables and noting the effects on a dependent variable: interpreting and presenting results in the form of a report that others can follow to replicate the experiment.

- Data Interpreting: Arriving at explanations, inference, or hypotheses from data that have been graphed or placed in a table.

\section{Method}

This research was divided into 2 phases that are (1) The study that related to theories, research and experts' opinion, (2) Evaluation on the proposed model.

\subsection{Phase 1: The Study that Related to Theories, Research, and Experts'Opinion}

The study in this phase included the study of theories and research on the problem-based learning, social media, searching technique and critical thinking, to be used as guidelines in determining learning processes and components of the model. The model will be designed after documentation review, and then the interview will be conducted to get an opinion towards the model from five experts.

\subsection{Phase 2: Evaluation on the Proposed Model}

After gathering all of information and modifying the model, three educational technology experts and two problem-based learning experts were selected to evaluate the model by using five scales model evaluation form. The expert selection criteria consisted of (1) the experts must have more than 3 years of experiences in the educational technology / problem-based learning field, (2) the experts must have a related work in educational technology /problem-based learning field, and (3) the experts must have experiences in designing or teaching with undergraduate students.

\section{Results}

4.1 Phase 1: Results of the Study that Related to Theories, Research, and Experts' Opinion. The Illustration of the Proposed Model, the Results can be seen in Figure 2 


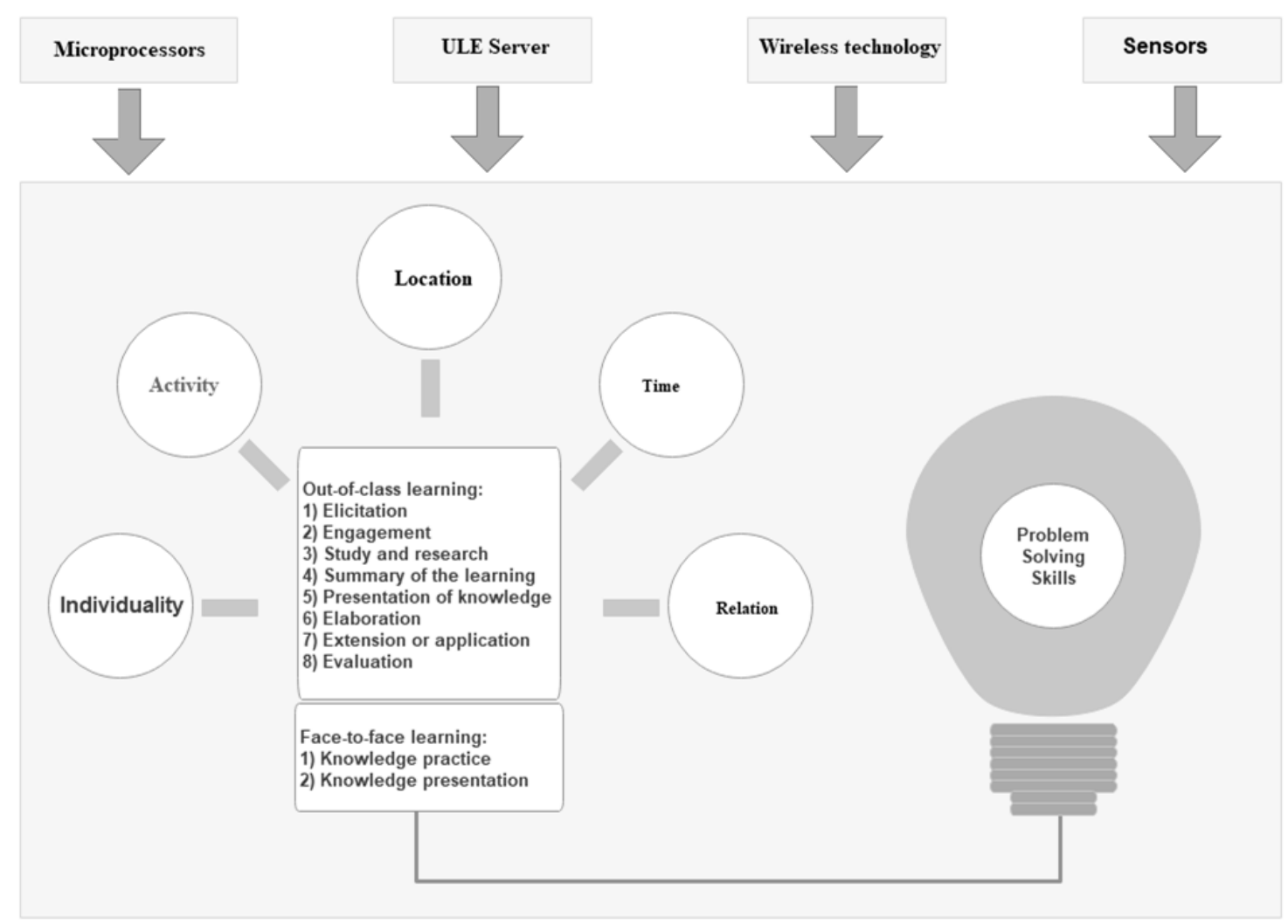

Figure 2. Ubiquitous Flipped Classroom Instructional Model with Learning Process of Scientific to Enhance Problem-Solving skills for Higher Education (UFC-PS Model)

\subsubsection{Ubiquitous Learning Environment (ULE) Includes}

- Microprocessors with memory will be embedded in every object or device (Stallings, 2013). The information each microprocessor will hold will be about the device. When a student approaches, the sensor detects their presence and will start relaying information to the students.

- ULE Server Module will include the Server, the Educational Strategies Database: The ULE server manages the network resources; The Educational Strategies Unit allows the application of strategies to reinforce student understanding through interaction and feedback. It analyses student responses to short questions and quiz returns more information or information in a different form when needed; DataBase - stores all the data about the devices, the users and the interactions that occur (Jones. \& Jo, 2004).

- Wireless technology - this will be in the form of Bluetooth and WiFi: Bluetooth has weak signal strength, uses little power a relatively short distance. Its low power consumption and ability to communicate with many devices is extremely beneficial when using handheld devices. WiFi based on the IEEE 802.11 specification has a range and speed that surpasses that of Bluetooth. It is compatible with any brand of Access Point and client hardware built to the IEEE 802.11 standard (Kumar, Aswal, \& Singh, 2013).

- Sensors will be used to detect any changes in surroundings. These will be placed adjacent to the devices and will be used to recognize the presence of students. The sensors used will include proximity, to detect movement, and light, to detect changes in light intensity (Jones \& Jo, 2004; Stallings, 2013).

\subsubsection{Ubiquitous Scaffolding (u-Scaffolding) Includes}

This scaffolding part can help the learners solve some problems that they cannot do by themselves in the process. This scaffolding part relies on the advantage of Ubiquitous learning; i.e. Context-awareness. Thereby, the assistance is based on learning contexts of learners including (Phumeechanya \& Wannapiroon, 2013): 
- Individuality: contexts about personal information of learners

- Activity: instructional activities such as learning results, test results, activity clues

- Location: the locations of learners

- Time: learning duration of students, appointments

- Relation: contexts about the relation between learners and friends, e.g. interaction between learners' group and instructors.

4.1.3 From the Synthesis of the Process of the Flipped Classroom Through Scientific Inquiry Comprise Eight Steps:

- Elicitation: Teachers give the students a pre-test and make notes on the knowledge and background of the students to serve as a guide to designing learning plans (Tanner \& Scott, 2015). This examination of knowledge can be done in many ways, such as conducting a brief lesson in which students answer allowing teachers to determine their basic knowledge. The data can then be used to plan instruction to suit the learners (Lage et al., 2011). The learners participate in planning their own learning by identifying the desired topic data source for data presentation and the criteria for evaluation of learning. Students are trained to identify issues such as education. The scope of the study is determined by consultation and guides teachers in identifying problems. The identification of problems helps to create enthusiastic learners in education and research who wish to find out more.

- Engagement: This is the step in which learners participate in the learning plan, including the learning channel and materials used in learning. They can also identify the topic about which they wish to learn more. Discussion and definition of the scope of the problem is even more evident within the group, which must identify ways to find the answer to a given problem (Syam, 2014). Teachers participate in the discussions to guide and ask for the links to the topic of the lesson. Students plan to search for and select relevant information in the study. With the resolution of the base or the conjecture, answers can be found to problems.

- Study and research: Teachers serve as a guide channel for students to study and research to find the answer to a given problem. Students must design the process study and research method, and manually select the sources. Students can select data sources according to their skills, such as video lectures of less than 20 minutes on YouTube, slides, books, websites such as Khan Academy, and lessons on the Tablet PC, etc. Such learning resources will then be placed in the Learning Management System, which is the system used to manage the online classroom (Zappe et al., 2009). Teachers can use the uploaded learning materials and tests, and can manage and track the learning outcomes. Students can check the results of their learning throughout the semester.

- Summary of the learning: This is the step in which the results of learning can be exchanged (Eisenkraft, 2003). If a problem arises or there are any questions, students can ask the instructor or their peers for knowledge within the group via a chat system or e-mail. If students are seeking a clear understanding, quizzes and homework assignments can help them to test their knowledge (Duran et al., 2011). The conclusion must be based on facts and theories that have studied during this process in which the teachers should provide advice and guidance closely. In this process, the students and teachers interact together in explaining about the lessons and the learning process and providing the correct theory for the students. Students understand and modify the learning outcomes to be clear and complete, summarizing the collected data. New knowledge is created, along with the testing of hypotheses and checking whether answers are valid or not.

- Presentation of knowledge: This is a classroom step in which the instructor places the students into small groups (Tanner \& Scott, 2015). One subject is chosen and a knowledgeable student can present to the class and discuss, along with results of the hypothesis testing. Errors may be discovered which can be an experience for all learners to study further, while teachers provide advice. Showing or sharing information is a step in the inquiry process where teachers can give students confidence in their work, and can develop presentation, communication and listening skills (Bergmann. \& Sams, 2012).

- Elaboration: This is the process of linking old and new knowledge. Through the activities, homework and post-test, the students can better understand the concepts (Lage et al., 2011). If they do not, they can seek help from peers and teachers immediately. Elaboration is a process of inquiry that enables students to draw conclusions to explain the situation. It helps the students to connect with the issues 
and contribute to the generation of wider knowledge.

- Extension or application: This is training in the processes where by students can apply their knowledge, concepts and theories in the creation of a piece of work or project (Zappe et al., 2009).

- Evaluation: This is the step of learner selfassessment, assessment of others, and teachers' evaluation activities (Eisenkraft, 2003). Evaluation of the inquiry process can encourage students to understand and assess their own capabilities. Teachers can assess the students' progress toward achieving the objectives of the study. Students can share their knowledge with each other (Tanner \& Scott, 2015) (Bergmann. \& Sams, 2012). Both the process and results must be considered, along with comparisons of the hypothesis and of the new knowledge with the prior knowledge.

\subsection{Phase 2: Evaluation on the Proposed Model}

The evaluation scores of the proposed model from three educational technology experts and two problem based learning experts were summarized in Table 1.

Table 1. Experts' evaluation scores of the proposed model

\begin{tabular}{lccc}
\hline Evaluation Lists & \multicolumn{2}{l}{ Results } & \multirow{2}{*}{ Appropriateness } \\
\cline { 2 - 3 } & $\overline{\mathrm{X}}$ & S.D. & \\
\hline Objective of the Model & 4.20 & 0.44 & Agree \\
Uses of Concepts and Principle & 4.60 & 0.54 & Strongly agree \\
Components of Model & 4.60 & 0.54 & Strongly agree \\
Process of Learning & 4.80 & 0.44 & Strongly agree \\
Overall & 4.55 & 0.49 & Strongly agree \\
\hline
\end{tabular}

In Table 1, the research found that the UFC-PS Model was evaluated at the agree level in Objective of the Model. Uses of Concepts and Principle, Components of Model, and Process of Learning were at the strongly agree level. Objective of the Model to enhance problem-solving skills for higher education. Concepts and Principle can be categorized into Ubiquitous learning environment, Flipped Classroom, Information problem solving, and Science process. Components of Model can be subdivided Ubiquitous Learning Environment, Ubiquitous Scaffolding, and flipped classroom through scientific inquiry. Examples of Process of Learning comprise eight steps are Elicitation, Engagement, Study and research, Summary of the learning, Presentation of knowledge, Elaboration, Extension or application, and Evaluation. The UFC-PS Model showed overall results at strongly agree level (arithmetic mean $=4.55$, standard deviation $=0.49$ ).

\section{Conclusion}

According to the document analysis that is associated with the process of flipped Classroom and process of scientific, together with ubiquitous in higher education, it was found that the UFC-PS Model enhanced problem-solving skills. ULE consists of four components: 1) microprocessors, which means to information each microprocessor will hold will be about the object; 2) ULE Server, ULE server manages the network resources; The Educational Strategies Unit allows for the application of strategies to reinforce and aid student understanding through interaction and feedback; 3) Wireless technology: WiFi, based on the IEEE 802.11 specification, has a range and speed which surpasses that of Bluetooth; and 4) Sensors, which means working with objects/devices and will be used to recognise the presence of students. U-Scaffolding consists of five aspects: 1) Individuality; 2) Activity; 3) Location; 4) Time; and 5) Relation. Flipped classroom through scientific inquiry comprises eight steps: 1) Elicitation; 2) Engagement; 3) Study and research; 4) Summary of the learning; 5) Presentation of knowledge; 6) Elaboration; 7) Extension or application; and 8) Evaluation.

\section{Acknowledgments}

This research was funded by Research and Development Institute and Faculty of Science and Technology, Rajabhat Maha Sarakham University, Thailand.

\section{References}

Alexander, B. (2004). Going Nomadic: Mobile Learning in Higher Education. Educause Review, 39(5), 28-35.

Ango, M. (2002). Mastery of science process skills and their effective use in the teaching of science: An Educology of science Education in the Nigerian context. International Journal of Educology, 16(1), 11-30.

Bergmann, J., \& Sams, A. (2012). Flip Your Classroom: Reach Every Student in Every Class Every Day. International Society for Technology in Education. 
Bishop, J. L., \& Verleger, M. A. (2013). The flipped classroom: a journey of research. Paper presented at the 120th ASEE Annual Conference \& Exposition.

Blair, E., Maharaj, C., \& Primus, S. (2016). Performance and perception in the flipped classroom. Education and Information Technologies, 21(6), 1465-1482. https://doi.org/10.1007/s10639-015-9393-5

Brand-Gruwel, S., Wopereis, I., \& Vermetten, Y. (2005). Information problem solving by experts and novices: Analysis of a complex cognitive skill. Computers in Human Behavior, 21, 487-508. https://doi.org/10.1016/j.chb.2004.10.005

Brand-Gruwel, S., Wopereis, I., \& Walraven, A. (2009). A descriptive model of information problem solving while using internet. Computers \& Education, 53, 1207-1217.

https://doi.org/10.1016/j.compedu.2009.06.004

Carpenter, R. G., Blythe, H., Sweet, C., Winter, R., \& Bunnell, A. (2015). A challenge for the flipped classroom: Addressing spatial divides. In A. G. Scheg (Ed.), Implementation and critical assessment of the flipped classroom experience. pp. 353. Hershey PA, USA: IGI Global. https://doi.org/10.4018/978-1-4666-7464-6.ch008

Cheng, K., \& Tsai, C. (2013). Affordances of Augmented Reality in Science Learning: Suggestions for Future Research. Journal of Science Education and Technology, 22, 449-462. https://doi.org/10.1007/s10956-012-9405-9

Chiappetta, E., \& Koballa, T. (2002). Science Instruction in the Middle and Secondary Schools (5th ed). Upper Saddle River, NJ: Merrill Prentice Hall.

Chatwattana, P., \& Nilsook, P. (2017.). A Web - based Learning System using Project - based Learning and Imagineering. International Journal of Emerging Technologies in Learning, 12(05), 4-22. https://doi.org/10.3991/ijet.v12i05.6344

Comber, D. P. M., \& Brady-Van den Bos, M. (2018). Too much, too soon? A critical investigation into factors that make Flipped Classrooms effective. Higher Education Research \& Development, 37(4), 683-697. https://doi.org/10.1080/07294360.2018.1455642

Duran, E., Duran, Lena, Haney, J., \& Scheuermann, A. (2011). A Learning Cycle for All Students (Online). Retrieved from http://people.uncw.edu/kubaskod/sec_406_506/classes/class_6_planning/learning_cycle.pdf

Eisenkraft, A. (2003). Expanding the 5e model, a proposed 7E model emphasizes transfer of learning and the importance of eliciting prior understanding, Science Education, 5(6), 57-59.

Hanson, J. (2016). Surveying the experiences and perceptions of undergraduate nursing students of a flipped classroom approach to increase understanding of drug science and its application to clinical practice. Nurse Education in Practice, 16, 79-85. https://doi.org/10.1016/j.nepr.2015.09.001

Harlen, W. (1999). Purposes and procedures for assessing science process skills. Assessment in Education, 6(1), 129-144. https://doi.org/10.1080/09695949993044

Hope, K. G., Rachel, E. S., \& Barbara, A. W. (2013). Using the Scientific Method to Guide Learning: An Integrated Approach to Early Childhood Curriculum. Early Childhood Education Journal, 41(5), 315-323. https://doi.org/10.1007/s10643-013-0579-4

Huang, Y. M., Liang, T. H., Su, Y. N., \& Chen, N. S. (2012). Empowering personalized learning with an interactive e-book learning system for elementary school students. Educational Technology Research and Development, 60(4), 703-722. https://doi.org/10.1007/s11423-012-9237-6

Hwang, G., Chu, H., Lin, Y., \& Tsai, C. (2011). A knowledge acquisition approach to developing mindtools for organizing and sharing differentiating knowledge in a ubiquitous learning environment. Computers \& Education, 57(1), 1368-1377. https://doi.org/10.1016/j.compedu.2010.12.013

Jantakoon, T., \& Piriyasurawong, P. (2018). Flipped Classroom Instructional Model with Mobile Learning Based On Constructivist Learning Theory to Enhance Critical Thinking (Fcmoc Model). Journal of Theoretical and Applied Information Technology, 96(16), 5607-5614.

Johnson, L. W., \& Renner, J. D. (2012). Effect of the flipped classroom model on a secondary computer applications course: student and teacher perceptions, questions and student achievement. (EdD. Dissertation), University of Louisville, Louisville, Kentucky. Retrieved from https://theflippedclassroom.files.wordpress.com/2012/04/johnson-renner-2012.pdf 
Jones, V., \& Jo, J. H. (2004). Ubiquitous learning environment: An adaptive teaching system using ubiquitous technology. In R. Atkinson, C. McBeath, D. Jonas-Dwyer \& R. Phillips (Eds), Beyond the comfort zone: Proceedings of the 21st ASCILITE Conference. 468-474. Perth, 5-8

Kirschner, P. A., Sweller, J., \& Clark, R. E. (2006). Why minimal guidance during instruction does not work: An analysis of the failure of constructivist, discovery, problem-based, experiential, and inquiry-based teaching. Educational Psychologist, 41, 75-86. https://doi.org/10.1207/s15326985ep4102_1

Kumar, A., Aswal, A., \& Singh, L. (2014). 4G Wireless Technology: A Brief Review 4G Wireless Technology: A Brief Review. International Journal of Engineering and Management Research, 3(2), 35-43

Lavelle, J. P., Stimpson, M. T., \& Brill, E. D. (2013). Flipped Out Engineering Economy: Converting a Traditional Class to an Inverted Model. Paper presented at the Industrial and Systems Engineering Research Conference.

Lage, J. M., Platt, J. G., \& Tregli, M. (2011). Inverting the Classroom: A Gateway to Creating an Inclusive Learning Environment. Journal of Economic Education, 31(1), 30-43. https://doi.org/10.1080/00220480009596759

Marinagi, C., Skourlas, C., \& Belsis, P. (2013). Employing Ubiquitous Computing Devices and Technologies in the Higher Education Classroom of the Future. Procedia-Social and Behavioral Sciences, 73, 487-494. https://doi.org/10.1016/j.sbspro.2013.02.081

Martin, F., \& Ertzberger, J. (2013). Here and now mobile learning: An experimental study on the use of mobile technology. Computers \& Education, 68, 76-85. https://doi.org/10.1016/j.compedu.2013.04.021

Mason, G. S., Shuman, T. R., \& Cook, K. E. (2013). Comparing the effectiveness of an inverted classroom to a traditional classroom in an upper-division engineering course. IEEE Transactions on Education, 56(4), 430-435. https://doi.org/10.1109/TE.2013.2249066

McCall, R., Wetzel, R., Loschner, J., \& Braun, A. K. (2011). Using presence to evaluate an augmented reality location aware game. Personal and Ubiquitous Computing, 15(1), 25-35. https://doi.org/10.1007/s00779-010-0306-8

Melhuish, K., \& Falloon, G. (2010). Looking to the future: M-learning with the iPad. Computers in New Zealand Schools. Learning, Leading, Technology, 22(3)

Ogata, H., \& Yano, Y. (2004). Context-Aware Support for Computer-Supported Ubiquitous Learning. Proceedings of the 2nd IEEE International Workshop on Wireless and Mobile Technologies in Education (pp. 27-34). https://doi.org/10.1109/WMTE.2004.1281330

Phumeechanya, N., \& Wannapiroon, P. (2013). Ubiquitous Scaffold Learning Environment Using Problem-Based Learning to Enhance Problem-Solving Skills. International Journal on Integrating Technology in Education (IJITE), 2(4), 23-33. https://doi.org/10.5121/ijite.2013.2403

Premsmith, J., Wannapiroon, P., \& Nilsook, P. (2017). Design of Challenge-Based Learning Activities on Ubiquitous Cloud Learning Environment Design of Challenge-Based Learning Activities on Ubiquitous Cloud Learning Environment, (April).

Quinn, C. (2000) mLearning: Mobile, wireless, in-your-pocket learning. LiNEZine. Retrieved from http://www.linezine.com/2.1/features/cqmmwiyp.htm

Serdyukov, P. (2015). Does online education need a special pedagogy?. Journal of Computing \& Information Technology, 23(1), 61-74. https://doi.org/10.2498/cit.1002511

Snape, P. M. (2017). Enduring Learning: Integrating C21st soft skills through Technology Education. Design and Technology Education: An International Journal, 22(3), 48-59.

Stallings, W. (2013). Computer organization and architecture (9th ed.). Pearson Education. Retrieved from http://www4.comp.polyu.edu.hk/ comp2421/\%289thEdition\%29\%28WilliamStallingsBooksonComputeran dDataCommunications\%29WilliamStallings-ComputerOrganizationandArchitecture-PrenticeHall\%282012 \%29.pdf

Syam, M. I. (2014). Possibility of Applying Flipping Classroom Method In Mathematics Classes In Foundation Program At Qatar University. Proceedings of SOCIOINT14-International Conference on Social Sciences and Humanities, 180-187. ISBN: 978-605-64453-1-6

Tanner, M., \& Scott, E. (2015). A flipped classroom approach to teaching systems analysis, design and 
implementation. Journal of Information Technology Education: Research, 14, 219-241. https://doi.org/10.28945/2266

Tsai, F. H., Tsai, C. C., \& Lin, K.Y. (2015). The evaluation of different gaming modes and feedback types on game-based formative assessment in an online learning environment. Computers \& Education, 81, 259-269. https://doi.org/10.1016/j.compedu.2014.10.013

White, J., \& Turner, H. (2011). Smartphone Computing in the Classroom. Education \& Training. IEEE Pervasive Computing. https://doi.org/10.1109/MPRV.2011.33

Yahya, S., Ahmad, E., \& Jalil, A. (2010). The definition and characteristics of ubiquitous learning. International Journal of Education and Development using Information and Communication Technology (IJEDICT), 6(1), 117-127.

Zappe, S., Leicht, R., Messner, J., Litzinger, T., \& Lee, H. (2009). “Flipping” the Classroom to Explore Active Learning in a Large Undergraduate Course. Proceedings of the 2009 American Society for Engineering Education Annual Conference and Exhibition.

\section{Copyrights}

Copyright for this article is retained by the author(s), with first publication rights granted to the journal.

This is an open-access article distributed under the terms and conditions of the Creative Commons Attribution license (http://creativecommons.org/licenses/by/4.0/). 